\title{
Non-Equilibrium Segregation due to the Beta-Alpha Reaction of Nickel-Aluminium Bronze Cast*
}

\author{
By Shoji Ueda** and Masato Zama**
}

\begin{abstract}
The equilibrium composition of the solid phase differs in general from that of the liquid phase, and segregation may occur which the composition of the solid phase formed at different times differs from the bulk compositions.

In the case of the $\beta \rightarrow \alpha$ transformation in nickel aluminium bronze castings, as well as in the solidification of solid solution, the composition of the coexisting $\beta$ and $\alpha$ phase have to change continuously. But the change requires diffusion, which at ideal condition remains incomplete in $\alpha$ phase, since the diffusion rate in $\alpha$ phase are comparatively low. So non-equilibrium eutectoid remains in the alloy containing 9 to $10 \%$ aluminium and $5 \%$ each of nickel and iron.

Theoretical approach has been also made for the degree of segregation which depends on the factors of the nucleation rate of the $\alpha$ phase.

It has been shown that under slow cooling conditions significant segregation can be expected if the nucleation rate is low.
\end{abstract}

(Received November 4, 1960)

\section{Introduction}

It is a well known fact that non-equilibrium segregation takes place when a solid solution solidifies from the melts under such cooling conditions that the diffusion of solute elements is incomplete in the solid phase as compared to that in the liquid phase. (1)

In such alloys that have solubility curves, between $\beta /(\alpha+\beta)$ and $(\alpha+\beta) / \alpha$, in copper-aluminium systems, it is confirmed by the present authors ${ }^{(4)}$ that segregation may occur in a solid/solid reaction due to the same mechanism as in a liquid/solid reaction, because the diffusion of aluminium is more difficult in the $\alpha$ phase

** Mitsubishi Shipbuilding and Engineering Co., Ltd. Nagasaki, Japan.

* This paper was published in Japanese in the Journal of the Japan Foundrymen's Society.

(1) E. Scheuer : Z. Metallk., 23 (1931), 237. than in the $\beta$ phase, $\dagger$ and that the non-equilibrium eutectoid $(\alpha+\delta)$ may precipitate due to the transformation of $\beta \rightarrow \alpha$ in the process of cooling even in those having a composition of the $\alpha$-mono phase in the equilibrium state.

In fact, the authors recognized this phenomenon in copper-aluminium binary alloy systems, ${ }^{(4)}$ and it is possible that the same phenomenon may also occur in

$\uparrow$ Though there is not much accurate data about the diffusion of aluminium in copper, this can be concluded from the fact that the higher the aluminium content, the greater the diffusion constant becomes, ${ }^{(2)}$ and that in copper-zinc alloy systems the diffusion constant in the $\beta$ phase is much greater than that in the $\alpha$ phase. (3)

(2) C. Matano: Japan J. Phys. 9 (1934), 41.

(3) W. Köhler : Zbl. Hütter u. Walzwerke 31 (1928), 650.

(4) S. Ueda and K. Morizane: This paper was read at the general meeting of JIM heald at Sapporo on Oct. (1960). 
nickel-aluminium bronze castings.

The equilibrium diagram(5) of aluminium bronze that contains $5 \%$ each of nickel and iron is shown in Fig. 1. As shown in the figure, the solubility limit of the $\alpha$ phase extends more than in a copper-aluminium

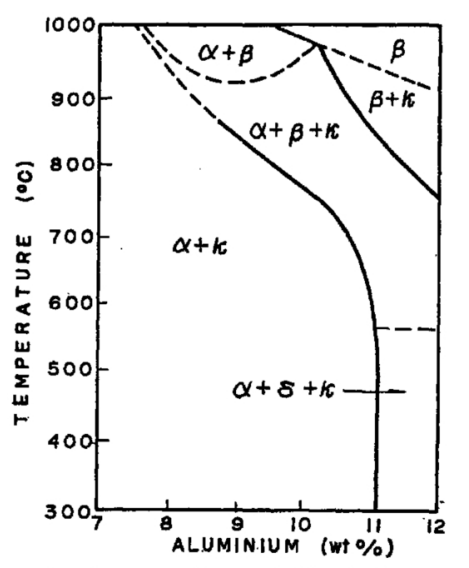

Fig. 1 Section of Cu-Al-Ni-Fe diagram at $5 \%$ eachiof $\mathrm{Fe}$ and $\mathrm{Ni}$.

binary alloy up to $11 \%$ of aluminium due to the addition of nickel and iron. Consequently, the alloys of practical composition of 9 to $10 \%$ aluminium become stabilized at the $(\alpha+\kappa)$ phase in the equilibrium state, and there can be no precipitation of eutectoid $(\alpha+\delta)$

However, in actual casting processes, the phenomenon of the precipitation of non-equilibrium eutectoid is perceived in the castings under a cooling condition in which the rate of cooling down to about $1000^{\circ} \mathrm{C}$, at which point a small amount of $\alpha$ phase precipitation originates, is low, in spite of the fact that they can be cooled more slowly under $1000^{\circ} \mathrm{C}$. (the rate of cooling of the casting of more than 30 tons in weight is less than $0.1^{\circ} \mathrm{C} / \mathrm{min}$.) three facts take place simultaneously :

(1) The alloy has the domain of the coexisting two phases (the domain of the coexistence of $(\alpha+\beta)$ in copper-aluminium systems) which is equivalent to the solidification temperature range.

Table 1 Composition of alloys used.

\begin{tabular}{c|c|c|c|c}
\hline \multirow{2}{*}{ Alloy No. } & \multicolumn{4}{|c}{ Chemical Composition, (\%) } \\
\cline { 2 - 5 } & $\mathrm{Cu}$ & $\mathrm{Al}$ & $\mathrm{Ni}$ & $\mathrm{Fe}$ \\
\hline & & & & \\
\hline & 81.27 & 8.70 & 4.90 & 5.08 \\
2 & 80.78 & 9.06 & 4.80 & 5.23 \\
3 & 80.71 & 9.34 & 4.70 & 5.23 \\
4 & 80.10 & 9.70 & 4.60 & 5.35 \\
5 & 79.93 & 9.82 & 4.67 & 5.28 \\
\hline
\end{tabular}

(2) The solubility limit curve has a suitable gradient for temperature and concentration.

(3) The diffusion of solute atoms in secondary precipitate phase ( $\alpha$ phase) is difficult to occur than in matrix phase ( $\beta$ phase).

Therefore, the segregation would not take place in nickel-aluminium bronze, too, as can be analogized from the case of solidification reaction, ${ }^{(6)}$ if the specimen is cooled slowly enough through the domain of the coexisting two phases and the diffusion of aluminium in $\alpha$ phase can be done sufficiently.

However, in case of casting such slow cooling through the domain of the coexisting two phases only occurs in the case of a large casting and in this case it is cooled also slowly in the course to the domain of coexisting two phases after its solidification. This fact has influence upon the nucleation rate of the $\alpha$ phase, and the change of the nucleation condition is considered to have a great influence on the segregation, therefore the author's present report deals mainly upon this

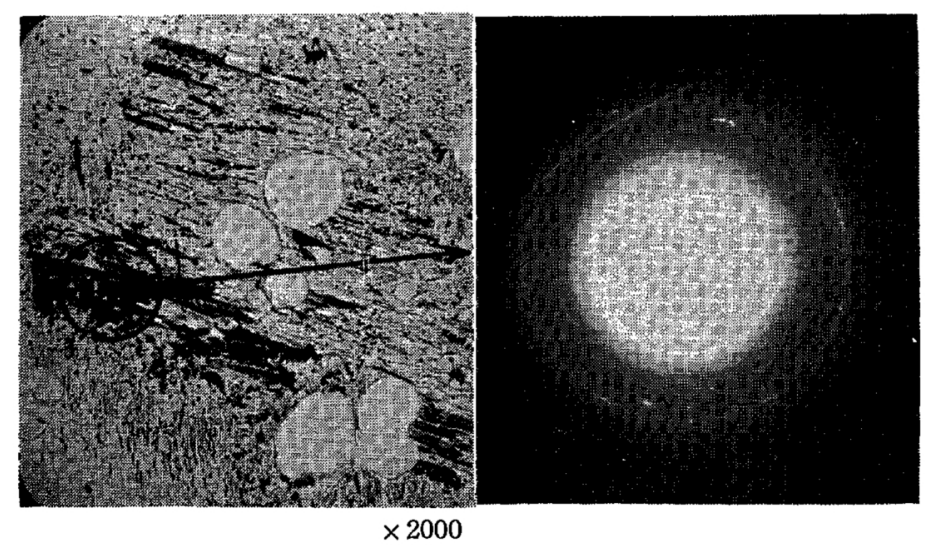

Photo. 1 Electron micro-structure of extraction replica and diffraction pattern.

\section{Specimens and Experimental Procedure}

Five kinds of copper-aluminium-nickel-iron quaternary alloys, made from high purity materials, as shown in Table 1, were melted in a crucible furnace and cast in a sand mould. The absence of impurity elements in each specimen was confirmed by spectral analysis.

It is considered that the segregation due to the solid/solid reaction also occurs when the following

(5) J. Mckeown et al : J. Inst. Metals 83 (1954 55), 69. point.

Each specimen was heated at $1000^{\circ} \mathrm{C}$ from one to two hundred hours to change the nucleation of the $\alpha$ phase and cooled at a constant rate of $0.5^{\circ} \mathrm{C} / \mathrm{min}$. down to $400^{\circ} \mathrm{C}$. The relationship between the number of $\alpha$ nuclei or radius of $\alpha$ grain and the quantity of precipitation of non-equilibrium eutectoid was. investigated microscopically. 
The fact that the non-equilibrium precipitation is eutectoid was previously confirmed by a preliminary experiment in which the above precipitate extracted by the replica method was interpreted to be the $\delta$ phase through electron diffraction technique. The results are shown in Photo. 1 and Table 2.

\begin{tabular}{|c|c|c|c|}
\hline \multicolumn{2}{|c|}{$\begin{array}{l}\text { Observed extracted particle from } \\
\text { alloy No. } 4\end{array}$} & \multicolumn{2}{|c|}{ 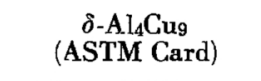 } \\
\hline$d(\AA)$ & $I$ & $d(\AA)$ & $I I_{0}$ \\
\hline $\begin{array}{l}3.440 \\
3.073 \\
2.895 \\
2.051 \\
1.982 \\
1.896 \\
1.693 \\
1.432 \\
1.409 \\
1.325 \\
1.286 \\
1.222 \\
1.176\end{array}$ & $\begin{array}{c}\text { M.S. } \\
\text { M.S. } \\
\text { W. } \\
\text { S. } \\
\text { S. } \\
\text { M.S. } \\
\text { W. } \\
\text { M. } \\
\text { W. } \\
\text { W. } \\
\text { W. } \\
\text { M. } \\
\text { S. }\end{array}$ & $\begin{array}{l}- \\
2.90 \\
2.05 \\
1.99 \\
1.95 \\
1.85 \\
1.70 \\
1.67 \\
1.45 \\
1.41 \\
1.34 \\
1.28 \\
1.26 \\
1.23 \\
1.18\end{array}$ & $\begin{array}{r}70 \\
100 \\
20 \\
20 \\
60 \\
50 \\
40 \\
80 \\
50 \\
20 \\
50 \\
60 \\
50 \\
100\end{array}$ \\
\hline
\end{tabular}

\section{Experimental Results}

In Fig. 2 the radius of $\alpha$-grain is shown as a function of the period held at $1000^{\circ} \mathrm{C}$, it shows that the longer the heating time at $1000^{\circ} \mathrm{C}$, the smaller the nucleation rate of the $\alpha$ phase becomes, resulting in the formation of a larger grain size of the $\alpha$ phase. The change of the rate of nucleation has an influence upon segregation even in the cooling process at the same rate from $1000^{\circ} \mathrm{C}$. The relationships between those are shown in Fig. 3 and Photo. 2 to 6 . It is hardly needed to note that these eutectoid disappear when heated at $550^{\circ} \mathrm{C}$ for a long time.

As mentioned above, the non-equilibrium segregation shows a tendency to increase under such cooling

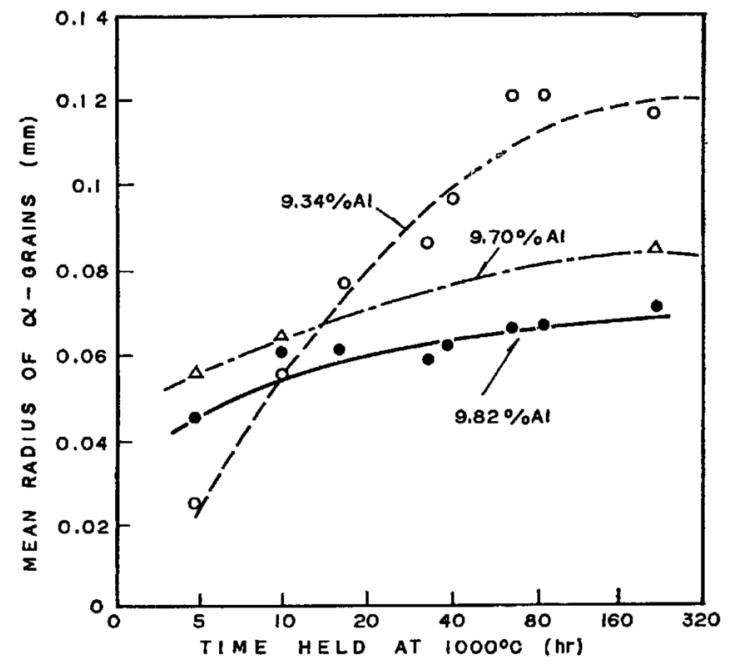

Fig. 2 The relationship between $\alpha$ grain size and time held at $1000^{\circ} \mathrm{C}$.

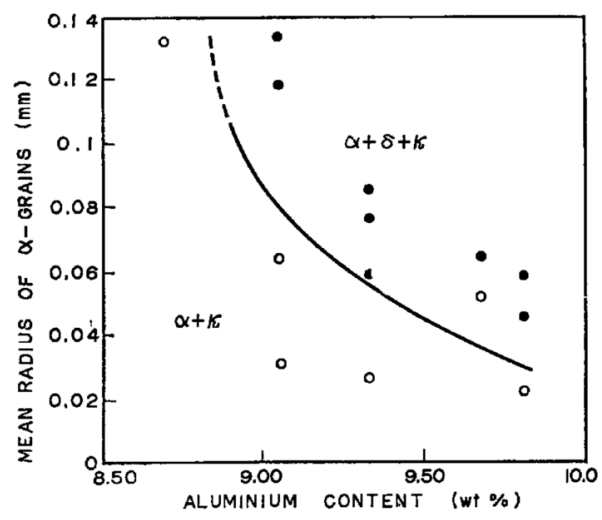

Fig. 3 The relationship between $\alpha$ grain size and $(\alpha+\delta)$ eutectoid precipitation.

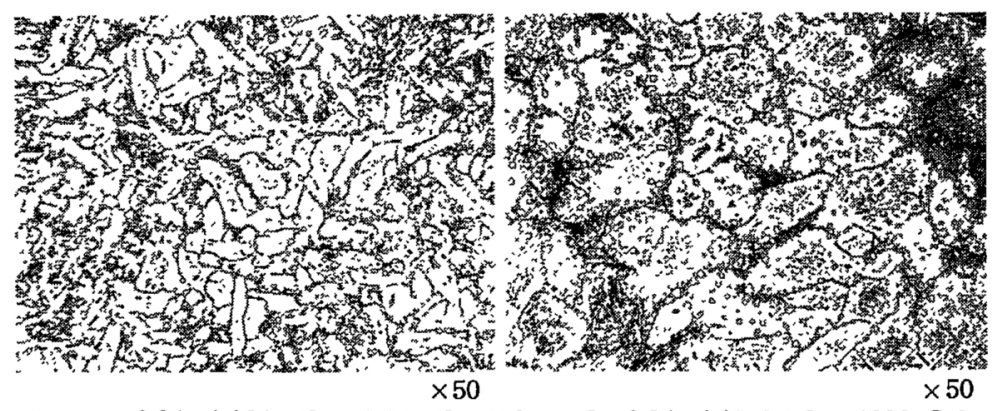

Photo. $29.34 \% \mathrm{Al}$ held at $1000^{\circ} \mathrm{C}$ Photo. $39.34 \% \mathrm{Al}$ held at $1000^{\circ} \mathrm{C}$ for $15 \mathrm{hrs}$. for 5 hrs. $\alpha+\kappa \quad \alpha+\kappa+$ eutectoid (dark field)

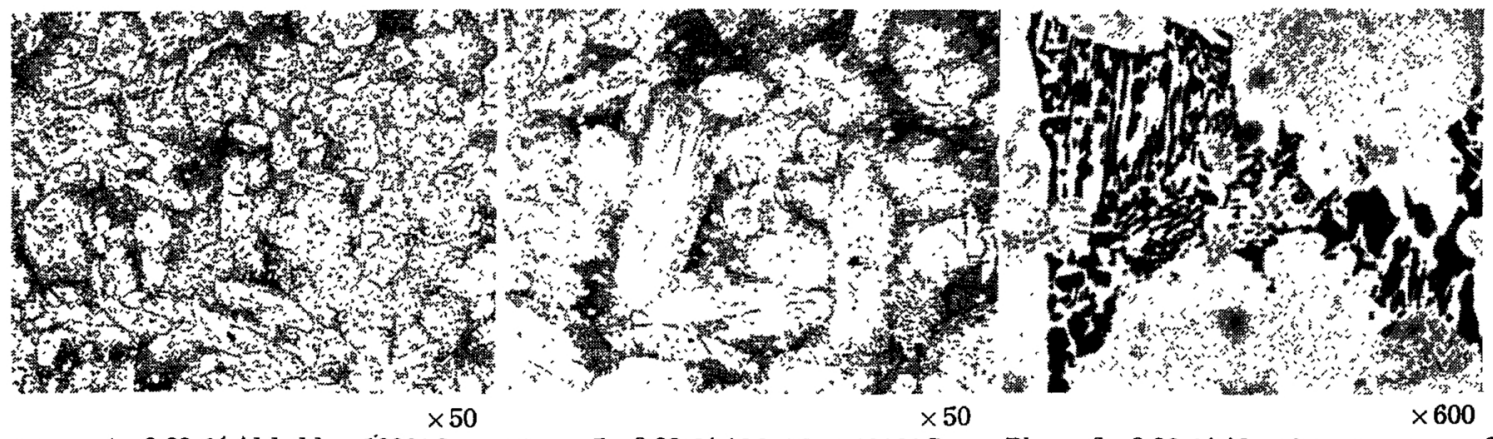

Photo. $49.82 \% \mathrm{Al}$ held at $1000^{\circ} \mathrm{C}$ for 5 hrs. $\alpha+\kappa+\delta$
Photo. $59.82 \% \mathrm{Al}$ held at $1000^{\circ} \mathrm{C}$ for 60 hrs. $\alpha+\kappa+\delta$
Photo. $6 \quad 9.82 \% \mathrm{Al}$ micro-structure of the non-equilibrium eutectoid. 
conditions that makes the nucleation rate of the $\alpha$ phase small. This means that, even in large castings cooled slowly, the slow cooling expedites the nonequilibrium segregation in such cases as it retards the rate of nucleation of the $\alpha$ phase.

\section{Discussion}

As is shown in this experiment, it can not simply be concluded that a slow cooling rate makes segregation difficult to occur. The question is why the segregation is accelerated when the nucleation rate of the $\alpha$ phase is small. This problem was studied under the following presuppositions :

(1) Nucleation rate of the $\alpha$ phase differs, but the rate of cooling in the domain of coexisting two phases is constant.

(2) The diffusion of aluminium in $\beta$ phase is complete.

(3) The relationship between the volume fraction $g$ and time $t$ in the $\beta \rightarrow \alpha$ transformation is given by the following equation :

$$
g \propto s 1-\exp \left(-b t^{n}\right)
$$

Assumption (1) satisfies the condition of this experiment, and assumption (2) is acceptable in case of a comparatively slow cooling rate. Assumption (3) is the formula frequently applied for isothermal transformation. However, since the conditions in which the transformation proceeds with nucleation and its growth and $d g / d t$ decreases after the mutual impingement of precipitate phase are considered in this formula, ${ }^{(7)}$ it can approximately be applied to the continuous cooling transformation, except in the case of extremely slow cooling.

In the sense of confirmation of assumption (3), the relation between the fraction transformed and time is sought by the experiment. The results are shown in Fig. 4. The curve obtained in this experiment is

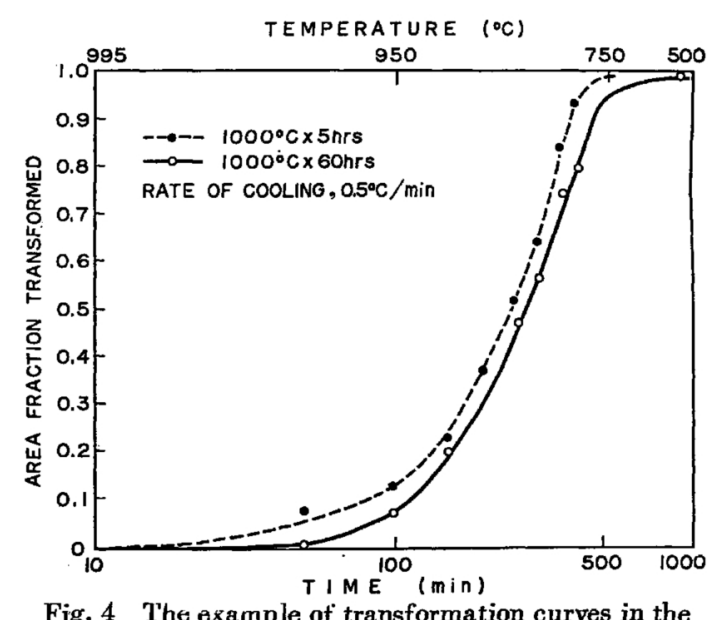

Fig. 4 The example of transformation curves in the $\beta \rightarrow \alpha$ reaction of Alloy No. 3 .

approximately the same as the curve of $\mathbf{n} \simeq 2$, since the $\alpha$ precipitates are in the forms of cylinders.

Under such conditions. Fig. 5 shows the processes of transformation in the different conditions of nucleation

(7) W.A.Johnson and R.F. Mehl : Trans. AIME 135(1939), 416. of the $\alpha$ phase when the transformation proceeds after being cooled for a certain time.

The number of nuclei of the $\alpha$ phase, rate of their growth (these decide $b$ in equation (1)) and the time decide $g$, and the partition ratio of concentration in $\alpha / \beta$.

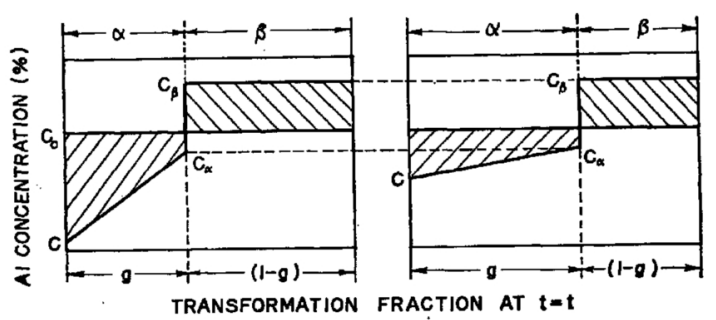

Fig. 5 Schematic representation of the relationship between the concentration gradient of solute in the $\alpha$ phase and fraction transformed.

interface, $\mathrm{C} \beta / \mathrm{C} \alpha$, is decided by phase diagram, and it remains the same notwithstanding the variation of $g$ as the temperature becomes equal after a certain time elapsed under the assumption (1).

And, $b$ is denoted as follows :

$$
\begin{aligned}
& b=f\left(I, v^{3}\right) \\
& I=F_{1} \exp \left(-\frac{E}{R T}\right) \\
& v=\alpha_{\lambda} \cdot F_{2} \exp \left(-\frac{A \alpha}{R T}\right)
\end{aligned}
$$

where, $I=$ the nucleation rate of $\alpha$ phase.

$v=$ the rate of radial growth of $\alpha$ phase.

$E=$ the activation energy for nucleation of $\alpha$ phase.

$\alpha_{1}=$ the growth coefficient of $\alpha$ phase.

$F_{1}, F_{2}=$ frequency factor.

$A_{\alpha}=$ the activation energy for diffusion of aluminium in $\alpha$ phase.

In this case, the concentration-dependance $\alpha_{\lambda}$ is naturally considered to be great, $i$. e. the rate of

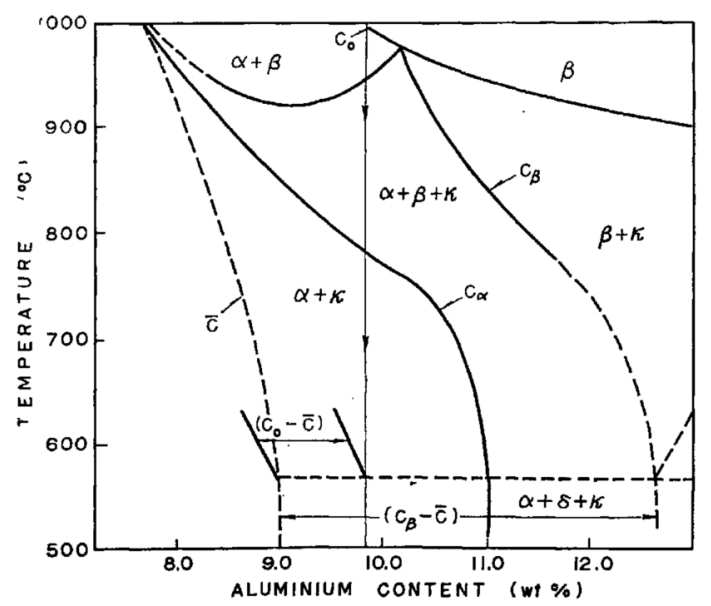

Fig. 6 Schematic representation of non-eguilibrium average concentration curve of the $\alpha$ phase, $\overline{\mathrm{C}}$.

growth $v$ becomes great under the condition in which $I$ became small, although the relationships betweens $F_{1}$, $E, F_{2}$ and $A \alpha$ are not well known because of the transformation at high temperatures. Consequently, the concentration gradient of aluminium in the $\alpha$ phase must be great when $g$ is small, for the smaller the rate 
of nucleation is, the less $g$ becomes.

Thus, the relation shown in Fig. 5 can be obtained. Since the area of the hatched parts in the figures must be equal to each other respectively :

$$
\left(C \beta-C_{o}\right) /\left(C_{o}-\bar{C}\right)=g /(1-g)
$$

where, $\bar{C}=$ average concentration of aluminium of $\alpha$ phase.

$C_{0}=$ concentration of aluminium in the alloy.

The quantity of non-equilibrium segregation can be found, as shown in Fig. 6 , if the variation of $\overline{\mathrm{C}}$ is given.

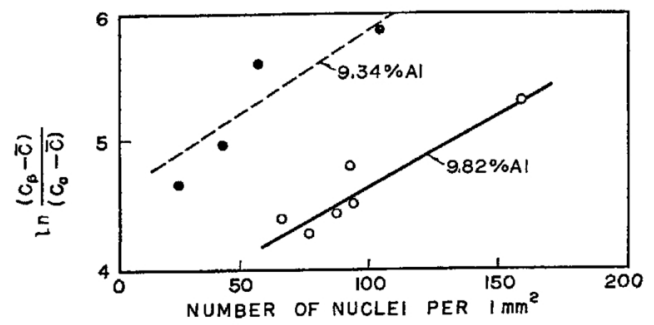

Fig. 7 The approximate relationship between nonequilibrium segregation and the nucleation rate.

Taking the formula (1) into the formula (5):

$$
(C \beta-\bar{C}) /\left(C_{o}-\bar{C}\right)=\exp \left(b t^{n}\right)
$$

This $b$ is, as mentioned before, denoted by the formula (2). However, since the change of the nucleation rate is considered to have great influences on the rate of growth, i. e. $v$ is the $I$-dependance, the variation of $b$ may be taken as a function of only $I$.

From the results shown in Fig 7, the formula (6) can be changed approximately as follows:

$$
\ln \frac{(C \beta-\bar{C})}{\left(C_{o}-\bar{C}\right)} \simeq K I
$$

where, $K=$ constant.

\section{Summary}

The following conclusions were obtained from the results of the experiments and the considerations that were carried out in order to analyze the phenomena of non-equilibrium segreg ation of nickel aluminium bronze castig :

(1) It is recognized in nickel aluminium bronze castings that non-equilibrium segregation takes place also in the solid/solid reaction by the same mechanism as in the solidification reaction.

(2) It can not be simply concluded that the smaller the rate of cooling is, the less the non-equilibrium segregation becomes. On the contrary, the slow rate of cooling expedites the segregation when it influences in such a way the slowing down of the rate of nucleation in the secondary precipitate phase. 